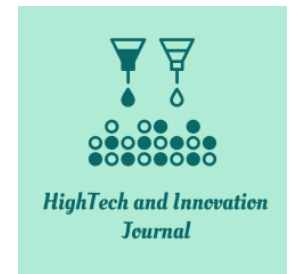

ISSN: $2723-9535$

\title{
CFD Study of Behavior of Transition Flow in Distinct Tubes of Miscellaneous Tape Insertions
}

\author{
Taiwo O. Oni ${ }^{1 *} \mathbb{0}$ \\ ${ }^{1}$ Department of Mechanical Engineering, Ekiti State University, Ado-Ekiti 360001, Nigeria.
}

Received 06 December 2021; Revised 13 February 2022; Accepted 14 February 2022; Available online 19 February 2022

\begin{abstract}
Application of transition flow can be found in several processes and systems. It has been revealed through findings from various researchers that the values of Reynolds numbers at which transition flow occurs vary. In the current work, investigations were numerically conducted by Fluent on transition of water flow in three assorted plain tubes fitted with miscellaneous tape insertions. They are plain tube with crossed-axes-circle-cut tape insert (C-C tube), plain tube with crossed-axes-triangle-cut tape insert (C-T tube), and plain tube with crossed-axes-ellipse-cut tape insert (C-E tube). The focus of the work is to explore the influence of the tape insertion on commencement and finish of transition flow in the tubes with respect to the Reynolds number of the flow. The Reynolds number (Re) taken into account for the transition flow is $2,150 \leq \operatorname{Re} \leq 4,650$, and the variation of Shear-Stress Transport $\kappa-\omega$ model that deals with transition flow was utilized. The results showed that transition flow starts at $\operatorname{Re}=2,300$ and finishes at $\operatorname{Re}=4,400$ in $\mathrm{C}$-T tube, starts at $\operatorname{Re}=2,780$ and finishes at $\operatorname{Re}=4,610$ in $\mathrm{C}-\mathrm{C}$ tube, but starts at $\operatorname{Re}=2,550$ and finishes at $\operatorname{Re}=4,500$ in $\mathrm{C}$-E tube. The Nusselt number in C-T tube is $19.3 \%$ to $45.6 \%$ higher than that in C-C tube, but the Nusselt number in C-T tube is $3.6 \%$ to $28.3 \%$ more than that in $\mathrm{C}$-E tube. The friction factor in $\mathrm{C}-\mathrm{T}$ tube is $2.15 \%$ to $4.56 \%$ higher than that in $\mathrm{C}-\mathrm{C}$ tube; the friction factor in C-T tube is $0.83 \%$ to $3.33 \%$ more than that in C-E tube. These results indicate that for the case of the tubes considered in this work, the C-T tube, which is the first one in which transition flow commences and ends, has the highest Nusselt number, but C-C tube, in which transition flow commences and finishes last, has the least Nusselt number. Interestingly, the same phenomenon applies to the friction factor.
\end{abstract}

Keywords: Heat Transfer; Transition Flow; Thermo-Hydraulic; Induced Tubes; Friction Factor; CFD.

\section{Introduction}

The intermediate condition of the flow of a fluid between laminar and turbulent states is known as transition flow. This means that its state falls between those of laminar and turbulent flows. It has been confirmed that transition flow is triggered by disturbances to the motion of a fluid [1].

Findings from various researchers have revealed that the values of Reynolds numbers at which transition flow occurs vary. The reason for this, as provided by Cengel [2] and Mullin [3], is that different mechanisms (for example, insertion of tapes inside the tube conveying the fluid, vibration of the tube, roughness of the inner surface of the tube, etc.) are responsible for generation of disturbances in fluid flows. It was observed by Reynolds [4], that depending on the disturbances in the flow, transition flow can occur at a Reynolds number of about 12,000. It was reported by Ekman [5] and Pfenniger and Lachman [6] that transition flow can start at a Reynolds number of about 40,000 and 10.000, respectively. Cengel [2] maintained that transition flow takes place at Reynolds numbers between 2,300 and 10,000 .

* Corresponding author: tooni1610@yahoo.com; taiwo.oni@eksu.edu.ng

dol) http://dx.doi.org/10.28991/HIJ-2022-03-02-02

$>$ This is an open access article under the CC-BY license (https://creativecommons.org/licenses/by/4.0/).

(C) Authors retain all copyrights. 
Transition flow occurs in the operation of aerospace and flows that encompass scramjets, interceptor missiles with divert jets, and ballistic missiles. It is also applied in power generation, automotive, chemical processing, and heating and cooling processes [7, 8]. The significance of intensifying the performance of heat transfer and fluid flow equipment has, no doubt, attracted the attention of many researchers, and has prompted them to carry out several investigations on thermo-hydraulic behaviour in transition flow. It has been reported by Bergles [9] and Manglik [10] that one of the means of achieving the intensification of the performance of equipment for heat transfer is the incorporation of twisted tapes, coils, etc. into a plain tube (also known as a smooth tube).

The thermo-hydraulic behaviour in laminar, transition, and turbulent flows was investigated experimentally by putting a helical wire coil inside a plain tube [11]. It was discovered that the combined helical wire coil and the plain tube yielded an acceleration of transition flow at a Reynolds number of 700. In the transition regime, the performance of the system was improved by the helical wire coil. Garcia et al. [12] presented an experimental analysis of laminar and transition flow in a plain tube fitted with wire coils and operated under uniform heat flux conditions and Reynolds numbers between 10 and 2,500. It was reported in the work that at Reynolds numbers between 1,000 and 1,300, there was a transition from laminar to turbulent flow. Another experimental study to determine the thermal-hydraulic performance in the transition flow of water in induced and plain tubes was carried out by another researchers [13]. The study's findings confirmed that transition occurred earlier in the induced tube. The transition for the plain tube occurred at a Reynolds number of 2,300, but it was at 1,900 for the induced tube.

Naik and Sundar (2014) investigated the convective heat transfer and friction factor characteristics of transition flow (2,500 Reynolds 10,000) of CuO nanoparticles of different sizes suspended in water/propylene glycol that flowed in a circular tube fitted with helical inserts of different twist ratios and another circular tube without inserts [14]. The Nusselt number obtained through nanofluid of $0.5 \%$ concentration was about $28 \%$ higher in the tube without the insertion, and was enhanced to 5.4 times over the water/propylene glycol when the helical insert was fitted to the flow channel. The friction factor obtained with the nanofluid was $10 \%$ higher in the tube without the insert and was increased to 1.4 times over the water/propylene glycol with the inclusion of the insert in the tube.

Martínez et al. [15] used a non-Newtonian fluid (1\% of carboxyl-methyl-cellulose solution in water) and a Newtonian fluid (propylene glycol) to present the behavior in laminar and transition flow in a plain tube on whose inside was inserted two different wire coils. The condition of the flow was such that Reynolds number was between 10 and 1,300. The results showed that at low Reynolds numbers, the effect of the wire coils could be neglected, that is the wire coils exhibited the behavior of a smooth tube. It was observed that the transition to turbulent flow was postponed to a Reynolds number of 500. For low Reynolds number below 500, the wire inserts were of no effect, but the effect became noticeable as turbulent flow was formed. Maximum Nusselt number enhancement of 7.5 times was obtained at a Reynolds number of 1,900 .

An analysis of flow and heat transfer in regime of laminar-transition flow with Reynolds number of 210 to 3,100 in pipes into which tape insertions were incorporated was examined numerically by Rossi et al. [16]. It showed that at low Reynolds numbers, there was a possibility of transition flow, caused by the tape inserts. There was also a possibility of transition to turbulent flow at a higher Reynolds number, but non-turbulent for pipes into which twistedtape inserts were not incorporated.

Experiments were executed through the effort of Meyer and Abolarin [17] to investigate the characteristics of heat transfer and pressure drop in the transition flow regime in a circular tube equipped with twisted tapes of different twist ratios. The Reynolds numbers under which the experiments were conducted were between 400 and 11,400. In addition, heat fluxes of between $2 \mathrm{~kW} / \mathrm{m}^{2}$ and $4 \mathrm{~kW} / \mathrm{m}^{2}$ were considered for the experiments. It was observed that higher heat flux delayed the transition from laminar to transition flow when the heat flux was altered, but the tape twist ratio was not altered. It was revealed that the friction factors increased as the twist ratio decreased. Moreover, when both the Reynolds number and the twist ratio were not altered, but the heat flux was increased, the friction factor dropped.

Chaware and Sewatkar [18] examined numerically the transition in flow in a pipe with twisted tape insert. The findings from the work indicated that at Reynolds number Re $\leq 700$, the flow was steady laminar and changed to periodic laminar flow at $700 \leq \operatorname{Re} \leq 1,126$. The flow was quasi-periodic in nature at $1,126 \leq \operatorname{Re} \leq 1,263$. There was transition to a chaotic behavior at $1,263 \leq \mathrm{Re} \leq 1,400$. Investigation on the heat transfer and pressure drop features in a circular pipe that has alternating clockwise and opposed-clockwise twisted tape inserts was carried out by Abolarin et al. [19]. In order to cover laminar, transition and turbulent flow regimes, the experiments were carried out at Reynolds numbers between 300 and 11,404. It was discovered that the connection angle between the two unlike twisted tape inserts has influence on the start and the end of the transition flow regime. Specifically, an increase in connection angle increased the heat transfer in the transition flow regime.

The transition flow of herba fluid in a circular tube was studied theoretically and experimentally by Hou [20]. The theoretical study was done by using a stability parameter. According to the results obtained from the two studies, accuracy of the results obtained from the theoretical study was better than that obtained from the experiment. 
Chaurasia and Sarviya [21] examined thermal hydraulic performance at transition flow regime of water in a tube fitted with a single strip helical screw insert and another one fitted with a double strip helical screw insert. It was observed that the tube with double strip helical screw insert has a better performance compared with the tube with a single strip helical screw insert. Investigation into bubbly-to-slug transition flows in a tube whose orientation was vertical was the focus of Dang et al. [22], in which the distinguishing features of air-water interfacial form was considered. It was concluded that the distinguishing features of the transition flows depends on velocity of the liquid (air-water) and ratio of the size of bubble to that of the tube.

Thus, literature review indicates that different investigations have been done on transition flow in induced tubes. Those literatures have revealed that attentions have not been focussed on transition flow in different plain tubes induced with distinct tape insertions. In the current work, investigations were conducted numerically on transition flow in distinct tubes of miscellaneous tape insertion. The focus is to explore the influence of the tape insertion on commencement and finish of transition flow in the tubes with respect to Reynolds number of the flow.

\section{Induced Tubes' Geometry}

The induced tubes used for the transition flow, as depicted in Figure 1(a-c), are plain tube with crossed-axescircle-cut tape insert (C-C tube), plain tube with crossed-axes-triangle-cut tape insert (C-T tube), and plain tube with crossed-axes-ellipse-cut tape insert (C-E tube). Part of the tubes is removed (as can be seen in Figure 1) so that the tape inserts are visible. The tape insert's pitch $(\mathrm{p}=0.054 \mathrm{~m})$, the tape insert's width $(\mathrm{b}=0.018 \mathrm{~m})$, the tube's radius $(\mathrm{r}=0.0095 \mathrm{~m})$, and the length of the tube $(\mathrm{L}=1.0 \mathrm{~m})$ are indicated in Figure 1.
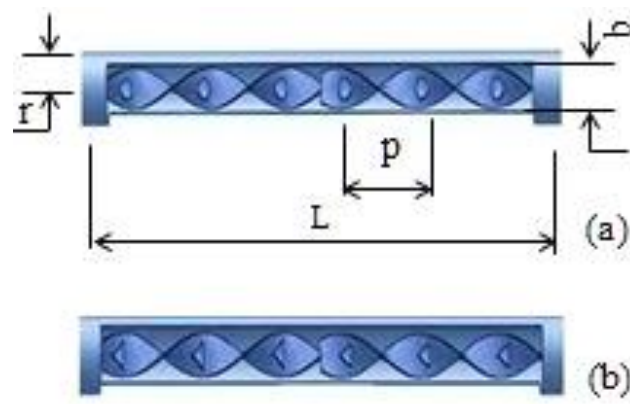

(b)

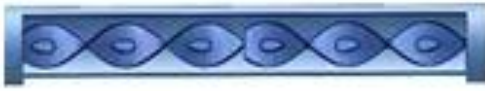

(c)

Figure 1. Induced tubes' geometries: (a) C-C tube, (b) C-T tube, (c) C-E tube

\section{Mathematical Modelling}

The transition flow was simulated by the Reynolds Averaged Navier-Stokes (RANS) equations [23] as;

Equation of continuity:

$$
\frac{\partial}{\partial \mathrm{x}_{\mathrm{i}}}\left(\mathrm{u}_{\mathrm{i}}\right)=0
$$

Equation of momentum:

$$
\frac{\partial\left(\rho u_{i}\right)}{\partial t}+\rho\left(u_{i} \frac{\partial u_{j}}{\partial x_{i}}\right)=-\frac{\partial p}{\partial x_{i}}+\frac{\partial}{\partial x_{i}}\left(\left(\mu+\mu_{t}\right) \frac{\partial u_{j}}{\partial x_{i}}\right)
$$

Equation of energy:

$$
\rho \mathrm{C}_{\mathrm{p}}\left(\frac{\partial \mathrm{T}}{\partial \mathrm{t}}+\mathrm{u}_{\mathrm{i}} \frac{\partial \mathrm{T}}{\partial \mathrm{x}_{\mathrm{i}}}\right)=-\frac{\partial}{\partial \mathrm{x}_{\mathrm{i}}}\left(\mathrm{k}_{\mathrm{eff}} \frac{\partial \mathrm{T}}{\partial \mathrm{x}_{\mathrm{i}}}\right)
$$

where $\mathrm{u}, \mathrm{T}, \mu, \mu_{\mathrm{t}}, \mathrm{k}_{\mathrm{eff}}, \mathrm{p}, \mathrm{C}_{\mathrm{p}}$, and $\rho$ are velocity, temperature, dynamic viscosity, turbulent viscosity, effective thermal conductivity, pressure, specific heat at constant pressure, and density, respectively.

Shear Stress Transport (SST) $\kappa-\omega$ and standard $\kappa-\omega$ are the different models considered for the transition flow. Because transition flow is partially turbulent, the variation of SST $\kappa-\omega$ model that deals with transition flow was used for the work. Its transport equations [23, 24] are given as Equations 4 and 5: 


$$
\begin{aligned}
& \frac{\partial}{\partial \mathrm{t}}(\rho \kappa)+\frac{\partial}{\partial \mathrm{x}_{\mathrm{i}}}\left(\rho \kappa \mathrm{u}_{\mathrm{i}}\right)=\frac{\partial}{\partial \mathrm{x}_{\mathrm{j}}}\left[\left(\mu+\frac{\mu_{\mathrm{t}}}{\sigma_{\mathrm{\kappa}}}\right) \frac{\partial \kappa}{\partial \mathrm{x}_{\mathrm{j}}}\right]+\mathrm{G}_{\mathrm{k}}-\beta_{1} \kappa \omega \\
& \frac{\partial}{\partial t}(\rho \omega)+\frac{\partial}{\partial x_{i}}\left(\rho \omega u_{i}\right)=\frac{\partial}{\partial x_{j}}\left[\left(\mu+\frac{\mu_{t}}{\sigma_{\omega}}\right) \frac{\partial \omega}{\partial x_{j}}\right]+G_{\omega}-\beta_{2} \omega^{2}+2\left(1-F_{1}\right) \sigma_{\omega, 2} \frac{1}{\omega} \frac{\partial \kappa}{\partial x_{j}} \frac{\partial \omega}{\partial x_{j}}
\end{aligned}
$$

where $\kappa, \omega$ are turbulence kinetic energy and specific dissipation rate, respectively; G denotes the generation of $\kappa, \omega$; $\sigma_{\kappa}, \sigma_{\omega}$ are turbulent Prandtl number for $\kappa$ and $\omega$, as indicated by the subscripts; $F_{1}$ is a blending function; $\beta_{1}, \beta_{2}$, and $\sigma_{\omega, 2}$ are model constants.

For the transitional model to be obtained, a factor $(\alpha)$ is incorporated to $\mu_{t}$ in equations above to depress the generation rate of turbulence [24]. Therefore, $\mu_{\mathrm{t}}$ is written as;

$$
\mu_{\mathrm{t}}=\frac{\rho \kappa}{\omega} \frac{1}{\max \left[\frac{1}{\alpha}, \frac{\mathrm{S} . \mathrm{F}_{2}}{\mathrm{a}_{1} \omega}\right]}
$$

It should be noted that $\alpha$ in Equation 6 is given as;

$$
\alpha=\alpha_{\infty}\left(\frac{\alpha_{0}+\mathrm{Re}_{\mathrm{t}} / \mathrm{R}_{\mathrm{k}}}{1+\mathrm{Re}_{\mathrm{t}} / \mathrm{R}_{\mathrm{k}}}\right)
$$

where $\alpha_{\infty}, \alpha_{0}, \beta_{\mathrm{i}}$, and $\mathrm{R}_{\mathrm{k}}$ are model constants, and $\alpha_{0}=\beta_{\mathrm{i}} / 3$ and $\mathrm{Re}_{\mathrm{t}}=\rho \kappa / \mu \omega$.

Also, the variation of standard $\kappa-\omega$ model that deals with transition flow, whose transport equations [24, 25] are given in Equations 8 and 9, was used for the work:

$$
\begin{aligned}
& \frac{\partial}{\partial \mathrm{t}}(\rho \kappa)+\frac{\partial}{\partial \mathrm{x}_{\mathrm{i}}}\left(\rho \kappa \mathrm{u}_{\mathrm{i}}\right)=\frac{\partial}{\partial \mathrm{x}_{\mathrm{j}}}\left[\left(\mu+\frac{\mu_{\mathrm{t}}}{\sigma_{\mathrm{\kappa}}}\right) \frac{\partial \kappa}{\partial \mathrm{x}_{\mathrm{j}}}\right]+\mathrm{G}_{\mathrm{k}}-\beta_{1} \kappa \omega \\
& \frac{\partial}{\partial \mathrm{t}}(\rho \omega)+\frac{\partial}{\partial \mathrm{x}_{\mathrm{i}}}\left(\rho \omega \mathrm{u}_{\mathrm{i}}\right)=\frac{\partial}{\partial \mathrm{x}_{\mathrm{j}}}\left[\left(\mu+\frac{\mu_{\mathrm{t}}}{\sigma_{\omega}}\right) \frac{\partial \omega}{\partial \mathrm{x}_{\mathrm{j}}}\right]+\mathrm{G}_{\omega}-\beta_{2} \omega^{2}
\end{aligned}
$$

The definition of the terms and the values for the model constants are as presented for the SST $\kappa-\omega$ above. In order to depress the generation rate of turbulence [24], $\mu_{t}$ is written as;

$$
\mu_{\mathrm{t}}=\alpha \frac{\rho \kappa}{\omega}
$$

The values for the model constants are as presented for the SST $\kappa-\omega$ above.

The tube wall was placed under uniformly-distributed heat flux and no-slip conditions. At the pipe intake, $301 \mathrm{~K}$ and $0.019 \mathrm{~m}$ were stated as temperature of fluid and conduit's diameter. The model constants specified were $\beta_{1}=$ $0.072, \beta_{2}=0.072, \sigma_{\omega, 2}=1.168, \mathrm{a}_{1}=0.31, \alpha_{\infty}=1, \beta_{\mathrm{i}}=0.072$, and $\mathrm{R}_{\mathrm{k}}=6$.

\section{Numerical Techniques}

Fluent, computational fluid dynamic software, was utilised to perform the study on the transition flow. The discretisation of the equations stated above was executed with second order upwind scheme which computes the quantities that are not known at the faces of the cell. As a mean of including the impact of pressure in solving the equation of momentum, the Semi Implicit Pressure Linked Equations algorithms [25] was made used of to join the calculations of pressure and velocity.

\section{Selection of a Felicitous Model}

For the purpose of selecting a proper model for the simulations, the variation of SST $\kappa-\omega$ and the variation of standard $\kappa-\omega$ models that deals with transition flow were employed. The values of temperature and velocity obtained at the end of the flow in the tube for $R e=2,300$ and $R e=4,650$ were compared, and presented in Figures 2 and 3.

As it can be seen in Figure 2(a) for $R e=2,300$, there is a negligible disparity between the temperature in the SST $\kappa-\omega$ and standard $\kappa-\omega$ models. Figure 2(b) shows that the disparity between the velocity in the SST $\kappa-\omega$ and standard $\kappa-\omega$ models is not noticeable. For $R e=4,650$, shown in Figure 3, a behaviour that is the same as that for the $R e=2,300$ (Figure 2) is observed in the temperature (Figure 3(a)) and velocity (Figure 3(b)). The results show that either the variation of SST $\kappa-\omega$ model or the variation of standard $\kappa-\omega$ model that deals with transition flow 
can be used. The variation of SST $\kappa-\omega$ model was chosen out of the two models. Its choice is based on the report [24] that it has ability to predict separation and reattachment better than the standard $\kappa-\omega$ model.
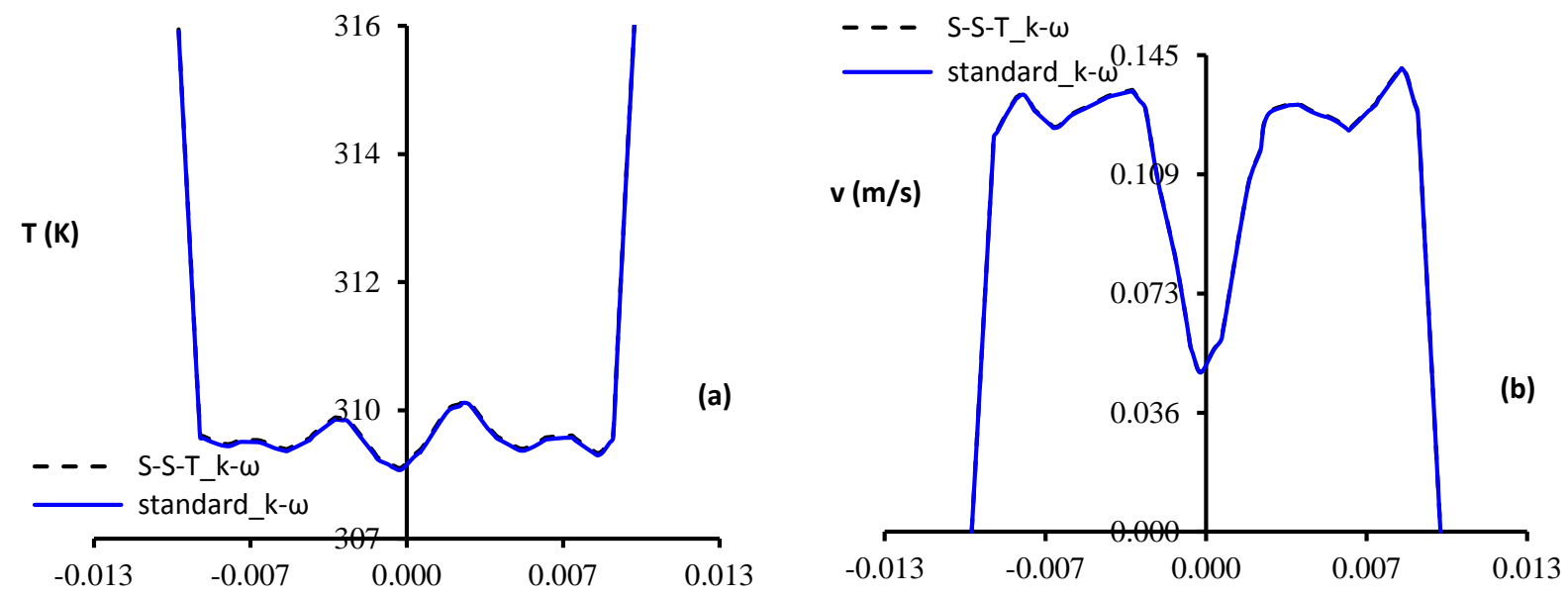

Figure 2. SST $\kappa-\omega$ model compared with standard $\kappa-\omega$ model for $R e=2,300$ : (a) temperature, (b) velocity
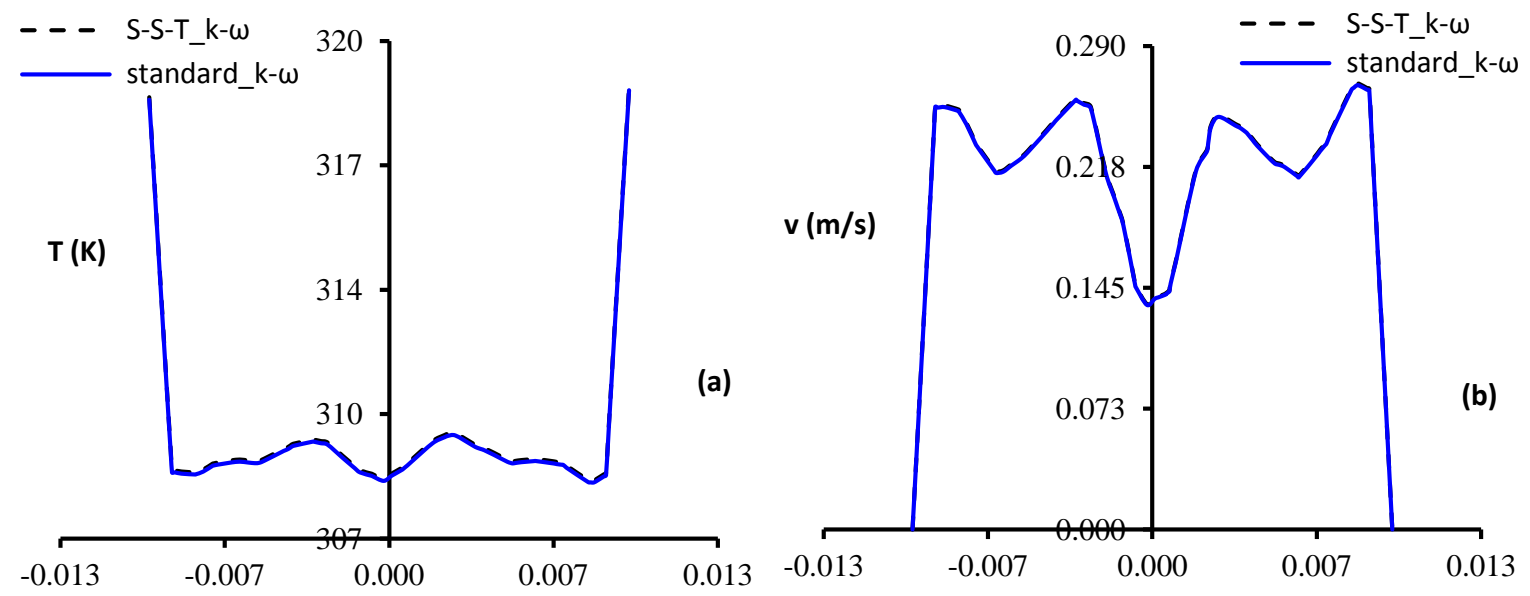

Figure 3. SST $\kappa-\omega$ model compared with standard $\kappa-\omega$ model for $R e=4,650$ : (a) temperature, (b) velocity

\section{Results and Discussion}

\subsection{Temperature}

The temperature for 2,150 $\leq R e \leq 4,650$ at axial location of $0.134 \mathrm{~m}$ before the flow end of the C-T tube's crosssection is presented in form of contours in Figure 4. For $R e=2,150$ (Figure 4(a)) and $\operatorname{Re}=2,300$ (Figure 4(b)), the temperature has a maximum value of $323.2 \mathrm{~K}$, and $326.3 \mathrm{~K}$, respectively. The maximum value of temperature increases to $329.1 \mathrm{~K}$ for $R e=4,400$ (Figure 4(c)) and increases further by $3.5 \mathrm{~K}$ for $R e=4,650$ (Figure 4(d)). The inference from the results is that there is a rise in the temperature for a rise in the Reynolds number. The cause of this occurrence is this: for an increment in Reynolds number, the fluid's viscous force is overcome by the fluid's momentum, and this results in generation of heat energy.
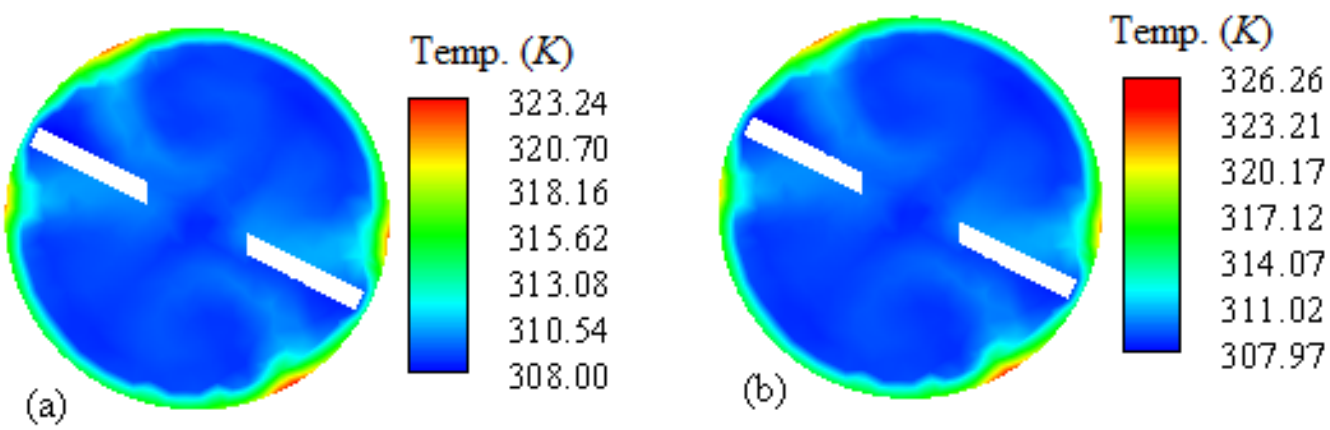

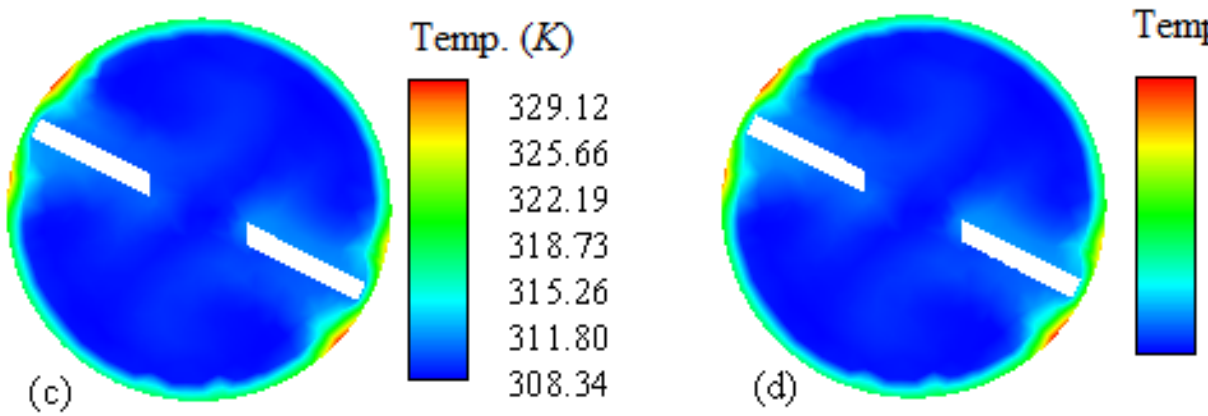

Temp. $(K)$

332.57

328.52

324.48

320.44

316.39

312.35

308.31

Figure 4. Temperature at axial location of $0.134 \mathrm{~m}$ before the flow end of the C-T tube's cross-section for (a) $R e=2,150$, (b) $\operatorname{Re}=2,300$, (c) $R e=4,400$, and (d) $R e=4,650$

\subsection{Velocity}

The velocity for Reynolds number between 2,300 and 4,650 at axial location of $0.134 \mathrm{~m}$ before the flow end of the C-T tube's cross-section is presented in Figure 5. In the case of $R e=2,150$ (Figure 5(a)) and $R e=2,300$ (Figure $5(\mathrm{~b})$ ), the velocity has a maximum value of $0.14 \mathrm{~m} / \mathrm{s}$ and $0.15 \mathrm{~m} / \mathrm{s}$, respectively. The maximum value of the velocity increases to $0.27 \mathrm{~m} / \mathrm{s}$ for $R e=4,400$ (Figure $5(\mathrm{c}$ )). As it can be seen, the maximum velocity for $R e=4,650$ (Figure $5(\mathrm{~d})$ ) is higher than that for $\operatorname{Re}=4,400$. The rise in the velocity as the Reynolds number rises is attributed to the force of the fluid's motion, which surmounts the fluid's viscous force.
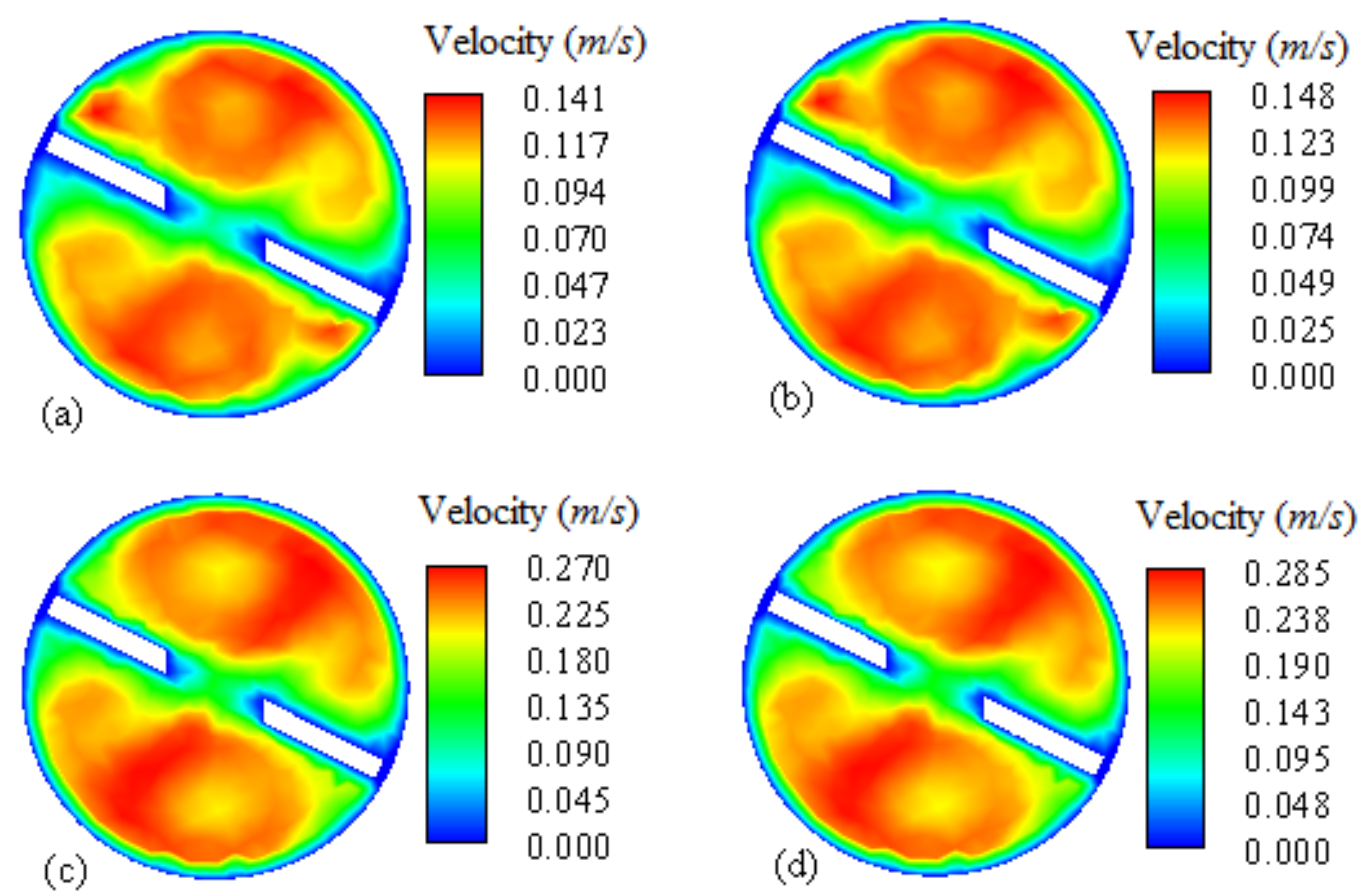

Figure 5. Velocity at axial location of $0.134 \mathrm{~m}$ before the flow end of the C-T tube's cross-section for (a) $R e=2,150$, (b) $R e=2,300$, (c) $R e=4,400$, and (d) $R e=4,650$

\subsection{Turbulent Kinetic Energy}

The turbulent kinetic energy (TKE) at axial location of $0.134 \mathrm{~m}$ before the flow end of the C-T tube's cross-section is shown in Figure 6. The values of turbulent kinetic energy for $\mathrm{Re}=2,150$ (Figure 6(a)) and $R e=2,300$ (Figure 6(b)) are approximately not different, being a maximum value of $0.0004 \mathrm{~m}^{2} / \mathrm{s}^{2}$ and $0.0005 \mathrm{~m}^{2} / \mathrm{s}^{2}$, respectively. By comparing the turbulent kinetic energy for $R e=4,400$ (Figure 6c)) and $R e=4,650$ Figure 6(d)) with those of the other Reynolds numbers, it can be observed that an increase in Reynolds number transforms to an increase in turbulent kinetic energy. The maximum turbulent kinetic energy for $R e=4,400$ and $R e=4,650$ are $0.0018 \mathrm{~m}^{2} / \mathrm{s}^{2}$ and $0.0019 \mathrm{~m}^{2} / \mathrm{s}^{2}$, respectively. 

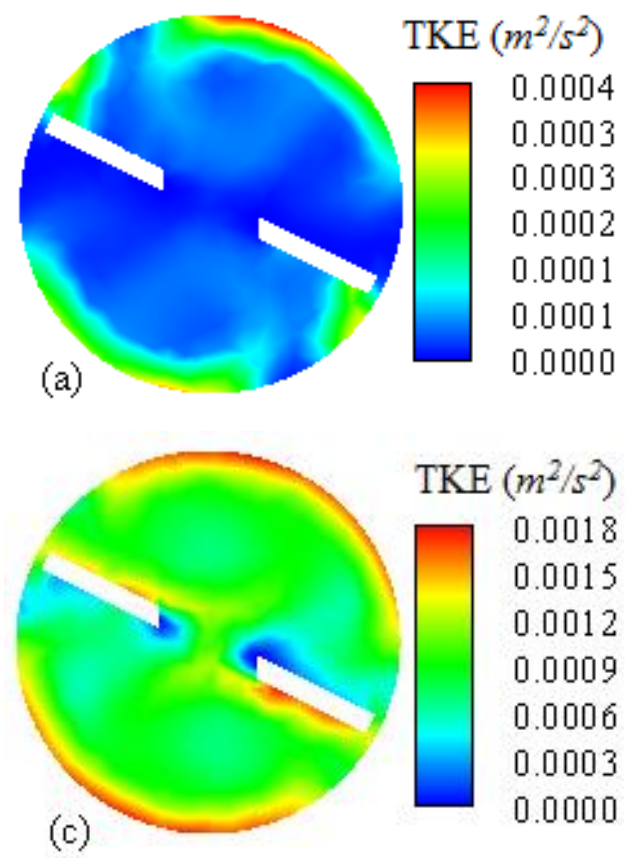
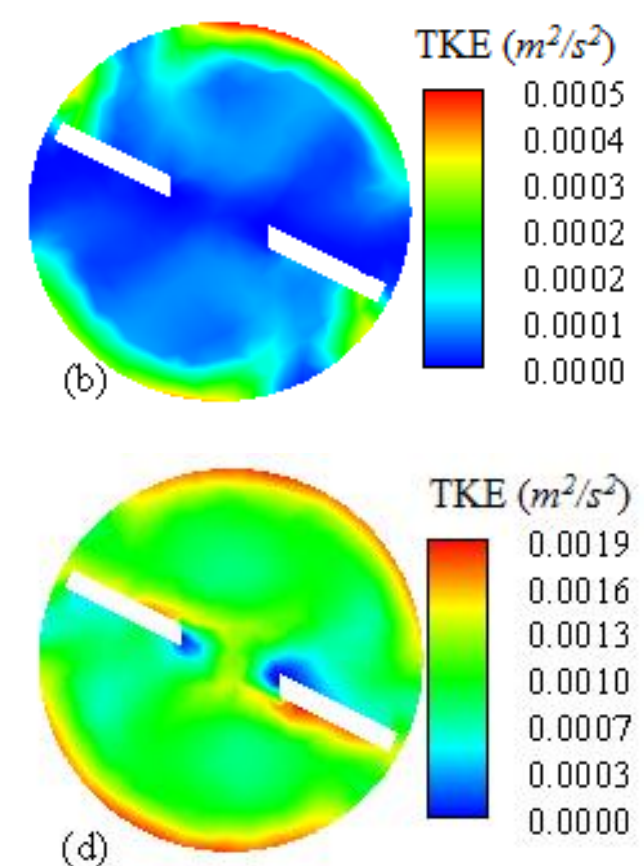

(d)

Figure 6. TKE at axial location of $0.134 \mathrm{~m}$ before the flow end of the C-T tube's cross-section for (a) $R e=2,150,(b)$ $R e=2,300$, (c) $\operatorname{Re}=4,400$, and (d) $\operatorname{Re}=4,650$

\subsection{Heat Transfer}

It is relevant to explore the influence of the tape insertions on commencement and finish of transition flow in the tubes with respect to Reynolds number of the flow. Therefore, the heat transfer in the three different tubes, namely C$\mathrm{C}$ tube, $\mathrm{C}-\mathrm{T}$ tube, and $\mathrm{C}$-E tube (mentioned in section 1 above) for laminar flow $(830 \leq R e \leq 2,000)$, transition flow $(2,150 \leq R e \leq 4,650)$, and turbulent flow $(5,000 \leq R e \leq 12,000)$ is discussed in this section.

Nusselt number $(\mathrm{Nu})$ is used to represent the transfer of heat in the tubes. The Nusselt number for the different flows in the tubes is presented in Figure 7. The beginning and finish of transition flow are indicated by triangular, square, and circular markers for the C-T tube, C-E tube, and C-C tube, respectively, on the graphs in Figure 7. For C-T tube, transition flow commences at $R e \leq 2,300$ and finishes at $R e \leq 4,400$. In the case of C-C tube, transition flow commences at $R e \leq 2,780$ and finishes at $R e \leq 4,610$, but for $\mathrm{C}$-E tube, it commences at $R e \leq 2,550$ and finishes at $R e \leq 4,500$. This means that transition flow commences and finishes earlier in C-T tube than in C-E tube, but it commences and finishes earlier in C-E tube than in C-C tube.

It is evident in Figure 7 that for the transition flow, the Nusselt number in C-T tube is $19.3 \%$ to $45.6 \%$ higher than that in C-C tube, but the Nusselt number in C-T tube is 3.6 to $28.3 \%$ higher than that in C-E tube. The relation between these Nusselt number's values in the tubes (C-T, C-E, and C-C) and the findings presented above that transition flow occurs first in C-T tube, then in C-E tube, and then in C-C tube clearly indicates that C-T tube, which is the first one in which transition flow commences and ends, has the highest Nusselt number, whereas C-C tube, in which transition flow commences and finishes last, has the least Nusselt number.

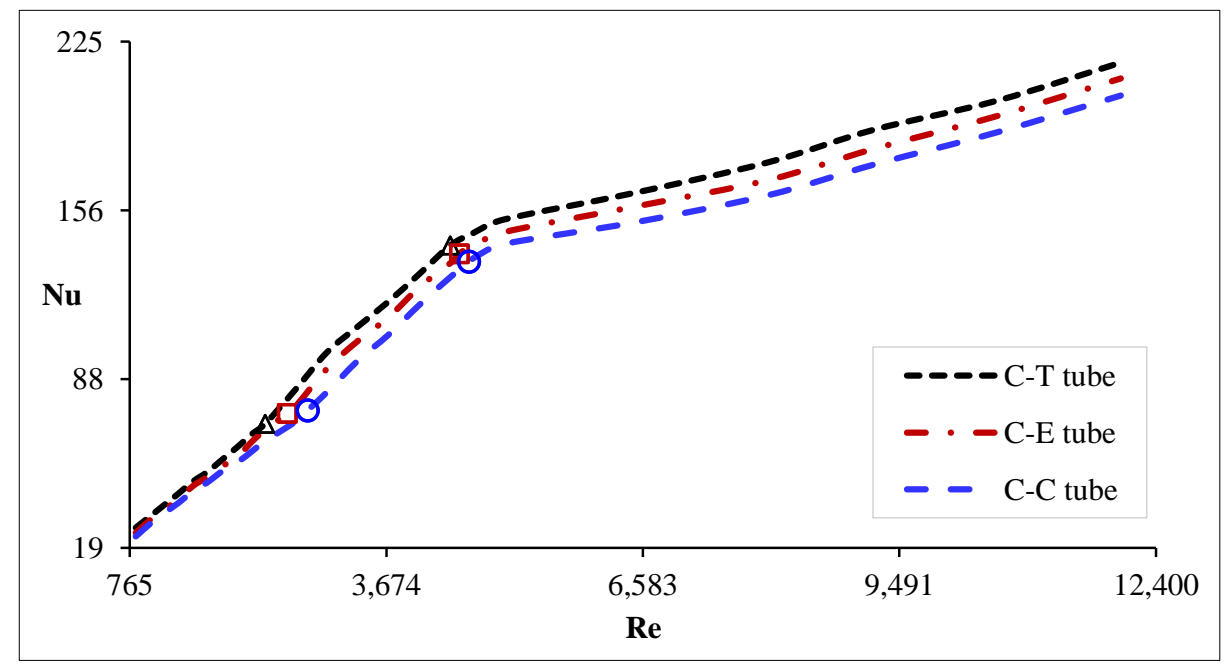

Figure 7. Nusselt number for the flows in the tubes 


\subsection{Friction Factor}

In this section, the C-C tube's, C-T tube's, and C-E tube's friction factor (f) are presented. The presentation is to know the effects of the tape insertions on the value of Reynolds number for the commencement and finish of transition flow.

Figure 8 depicts the friction factor for laminar flow $(830 \leq R e \leq 2,000)$, transition flow $(2,150 \leq R e \leq 4,650)$, and turbulent flow $(5,000 \leq R e \leq 12,000)$ in the tubes. The different markers (triangular, square, and circular) on the graphs in the figure indicate the commencement and finish of transition flow in the C-T tube, C-E tube, and C-C tube, respectively. Transition flow commences in $\mathrm{C}$ - $\mathrm{T}$ tube at $R e=2,300$, followed by $\mathrm{C}-\mathrm{E}$ tube at $R e=2,550$, and then in $\mathrm{C}-\mathrm{C}$ tube at $R e=2,780$. It ends in $\mathrm{C}-\mathrm{T}$ tube, $\mathrm{C}$-E tube, and $\mathrm{C}-\mathrm{C}$ tube at $R e=4,400, R e=4,550$, and $R e=4,610$, in that order.

For the transition flow, as demonstrated in Figure 8, the friction factor in C-T tube is $2.15 \%$ to $4.56 \%$ higher than that in $\mathrm{C}-\mathrm{C}$ tube, whereas the friction factor in $\mathrm{C}-\mathrm{T}$ tube is $0.83 \%$ to $3.33 \%$ higher than that in $\mathrm{C}$-E tube. As in the case of the Nusselt number discussed above, it can be observed that $\mathrm{C}-\mathrm{T}$ tube, which is the first one in which transition flow commences and ends, has the highest friction factor, whereas $\mathrm{C}-\mathrm{C}$ tube, in which transition flow commences and finishes last, has the least friction factor.

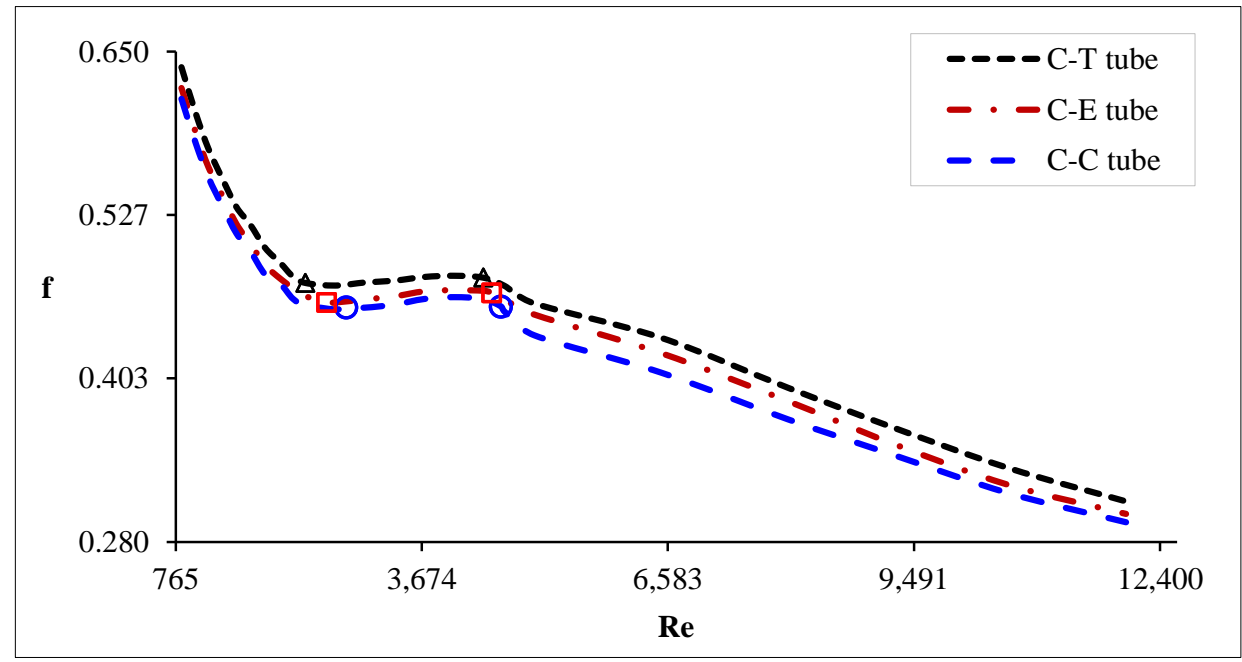

Figure 8. Friction factor for the flows in the tubes

\section{Conclusion}

In an attempt to explore the effects of the tape insertions on the commencement and finish of transition flow in tubes with respect to the Reynolds number of the flow, investigations were conducted numerically on the transition flow of water through three assorted tubes, namely plain tube with crossed-axes-circle-cut tape insert (C-C tube), plain tube with crossed-axes-triangle-cut tape insert (C-T tube), and plain tube with crossed-axes-ellipse-cut tape insert (C-E tube).

The indication from the findings is that the values of Reynolds numbers at which transition flow occurs vary, and that these values depend on the type of tape insertion inside the tubes conveying the fluid. The discovery further shows that transition commences and finishes first in the C-T tube, then in the C-E tube, and then in the C-C tube. The Nusselt number and friction factor in the C-T tube are greater than those in the C-E tube, but the Nusselt number and friction factor in the $\mathrm{C}-\mathrm{E}$ tube are greater than those in the $\mathrm{C}-\mathrm{C}$ tube. The $\mathrm{C}-\mathrm{T}$ tube, which is the first one in which transition flow commences and ends, has the highest Nusselt number, but the $\mathrm{C}-\mathrm{C}$ tube, in which transition flow commences and finishes last, has the least Nusselt number. The same trend applies to the friction factor.

\section{Declarations}

\subsection{Data Availability Statement}

The data presented in this study are available on request from the corresponding author.

\subsection{Funding}

The author received no financial support for the research, authorship, and/or publication of this article. 


\subsection{Declaration of Competing Interest}

The author declare that there are no known competing financial interests or personal relationships that could have appeared to influence the work reported in this paper.

\section{References}

[1] Reynolds, O. (1883). An experimental investigation of the circumstances which determine whether the motion of water shall be direct or sinuous, and of the law of resistance in parallel channels. Philosophical Transactions of the Royal Society of London, 174, 935-982. doi:10.1098/rstl.1883.0029.

[2] Cengel, Y. A. (2002). Table A-15 Properties of air at 1 atm pressure. Heat Transfer and Mass Transfer-A Practical Approach, 3rd ed. McGraw-Hill: New York, NY, USA.

[3] Mullin, T. (2011). Experimental studies of transition to turbulence in a pipe. Annual Review of Fluid Mechanics, 43, 1-24. doi:10.1146/annurev-fluid-122109-160652.

[4] Reynolds, O. (1895). On the dynamical theory of incompressible viscous fluids and the determination of the criterion. Philosophical Transactions of the Royal Society of London. (A.), 186, 123-164. doi:10.1098/rsta.1895.0004.

[5] Ekman, V. W. (1910). On the change from steady to turbulent motion of liquids. In Arkiv för Matematik, Astronomi och Fysik, 6(12). Almqvist \& Wiksell, Sweden.

[6] Pfenniger, W., \& Lachman, G. V. (1961). Boundary layer and flow control. GV Lachmann, Ed. 2, 970, Pergamon. doi:10.1016/c2013-0-08248-5.

[7] Qian, S., Wu, J., Xu, H., \& Ma, F. (2021). Transition flow occurrence on stepped channels. Journal of Hydraulic Research, 1-9. doi:10.1080/00221686.2021.1978569.

[8] Piotrowski, M. G. H., \& Zingg, D. W. (2021). Smooth Local Correlation-Based Transition Model for the Spalart-Allmaras Turbulence Model. AIAA Journal, 59(2), 474-492. doi:10.2514/1.j059784.

[9] Bergles, A. E. (1998). Techniques to enhance heat transfer. In Rohsenow, W. M., Hartnett, J. P., \& Cho, Y. I. (Editors), Handbook of Heat Transfer. Chapter 11, pages 11.1 - 11.76. McGraw-Hill, New York, NY, USA.

[10] Manglik, R. M. (2003). Heat transfer enhancement. In Bejan, A., \& Kraus, A. D. (Editors), Heat Transfer Handbook. Chapter 14, pages 1029 - 1130. John Wiley \& sons, New Jersey, NJ, USA.

[11] Abbaspour, M., Mousavi Ajarostaghi, S. S., Hejazi Rad, S. A. H., \& Nimafar, M. (2021). Heat transfer improvement in a tube by inserting perforated conical ring and wire coil as turbulators. Heat Transfer, 50(6), 6164-6188. doi:10.1002/htj.22167.

[12] García, A., Solano, J. P., Vicente, P. G., \& Viedma, A. (2007). Enhancement of laminar and transitional flow heat transfer in tubes by means of wire coil inserts. International Journal of Heat and Mass Transfer, 50(15-16), 3176-3189. doi:10.1016/j.ijheatmasstransfer.2007.01.015.

[13] Liao, G., Li, Z., Zhang, F., Liu, L., \& E, J. (2021). A Review on the Thermal-Hydraulic Performance and Optimization of Compact Heat Exchangers. Energies, 14(19), 6056. doi:10.3390/en14196056.

[14] Naik, M. T., \& Sundar, L. S. (2014). Heat Transfer and Friction Factor with Water/Propylene Glycol-Based CuO Nanofluid in Circular Tube with Helical Inserts under Transition Flow Regime. Heat Transfer Engineering, 35(1), 53-62. doi:10.1080/01457632.2013.810451.

[15] Martínez, D. S., García, A., Solano, J. P., \& Viedma, A. (2014). Heat transfer enhancement of laminar and transitional Newtonian and non-Newtonian flows in tubes with wire coil inserts. International Journal of Heat and Mass Transfer, 76, 540548. doi:10.1016/j.ijheatmasstransfer.2014.04.060.

[16] Rossi, R., Cattani, L., Mocerino, A., Bozzoli, F., Rainieri, S., Caminati, R., \& Pagliarini, G. (2017). Numerical analysis of flow resistance and heat transfer in the transitional regime of pipe flow with twisted-tape turbulators. Journal of Physics: Conference Series, 923(1), 12033. doi:10.1088/1742-6596/923/1/012033.

[17] Meyer, J. P., \& Abolarin, S. M. (2018). Heat transfer and pressure drop in the transitional flow regime for a smooth circular tube with twisted tape inserts and a square-edged inlet. International Journal of Heat and Mass Transfer, 117, 11-29. doi:10.1016/j.ijheatmasstransfer.2017.09.103.

[18] Chaware, P., \& Sewatkar, C. M. (2019). Flow transitions for flow through a pipe with a twisted tape insert. Transactions of the American Society of Mechanical Engineers, Journal of Fluids Engineering, 141, 111110.1-111110.10. doi:10.1115/1.4043557.

[19] Abolarin, S. M., Everts, M., \& Meyer, J. P. (2019). Heat transfer and pressure drop characteristics of alternating clockwise and counter clockwise twisted tape inserts in the transitional flow regime. International Journal of Heat and Mass Transfer, 133, 203-217. doi:10.1016/j.ijheatmasstransfer.2018.12.107. 
[20] Hou, Z. (2020). The transition of herba fluid flow patten in a circular tube. IOP Conference Series: Materials Science and Engineering, 768(4), 42049. doi:10.1088/1757-899X/768/4/042049.

[21] Chaurasia, S. R., \& Sarviya, R. M. (2021). Comparative thermal hydraulic performance analysis on helical screw insert in tube with different number of strips in transition flow regime. Heat and Mass Transfer/Waerme- Und Stoffuebertragung, 57(1), 7791. doi:10.1007/s00231-020-02934-6.

[22] Dang, Z., Wang, G., \& Ishii, M. (2021). Two-phase interfacial structure of bubbly-to-slug transition flows in a $12.7 \mathrm{~mm}$ ID vertical tube. International Journal of Heat and Mass Transfer, 165, 120556. doi:10.1016/j.ijheatmasstransfer.2020.120556.

[23] Abraham, J. P., Sparrow, E. M., \& Tong, J. C. K. (2009). Heat transfer in all pipe flow regimes: laminar, transitional/intermittent, and turbulent. International Journal of Heat and Mass Transfer, 52(3-4), 557-563. doi:10.1016/j.ijheatmasstransfer.2008.07.009.

[24] Fluent. (2006). Fluent User's Guide. Computational fluid dynamic software, Fluent Inc, New York, NY, USA.

[25] Patankar, S. V., \& Spalding, D. B. (1972). A calculation procedure for heat, mass and momentum transfer in three-dimensional parabolic flows. International Journal of Heat and Mass Transfer, 15(10), 1787-1806. doi:10.1016/0017-9310(72)90054-3. 